\title{
Scenarios of climate change
}

\author{
H. Graß1
}

Max-Planck-Institute for Meteorology, Hamburg, Germany

\begin{abstract}
This article provides an overview of current and prospected climate changes, their causes and implied threats, and of a possible route to keep the changes within a tolerable level. The global mean temperature has up to 2005 risen by almost $0.8^{\circ} \mathrm{C}$, and the change expected by 2100 is as large as glacial-interglacial changes in the past, which were commonly spread out over 10000 years. As is well known, the principle actor is man-made $\mathrm{CO}_{2}$, which, together with other anthropogenic gases, enhances the atmosphere's greenhouse effect. The only man-made cooling agent appears to be atmospheric aerosols. Atmospheric $\mathrm{CO}_{2}$ has now reached levels unprecedented during the past several million years. Principal threats are a greatly reduced biodiversity (species extinction), changes in the atmospheric precipitation pattern, more frequent weather extremes, and not the least, sea level rise. The expected precipitation pattern will enhance water scarcity in and around regions that suffer from water shortage already, affecting many countries. Sea level rise will act on a longer time scale. It is expected to amount to more than $50 \mathrm{~cm}$ by 2100 , and over the coming centuries the potential rise is of the order of $10 \mathrm{~m}$. A global-mean temperature increase of $2{ }^{\circ} \mathrm{C}$ is often quoted as a safe limit, beyond which irreversible effects must be expected. To achieve that limit, a major, rapid, and coordinated international effort will be needed. Up to the year 2050, the man-made $\mathrm{CO}_{2}$ releases must be reduced by at least $50 \%$. This must be accompanied by a complete overhaul of the global energy supply toward depending increasingly on the Sun's supply of energy, both directly and in converted form, such as wind energy. Much of the information and insight available today has been generated by the Intergovernmental Panel on Climate Change (IPCC), in particular its Fourth Assessment Report of 2007, which greatly advanced both public attention and political action.
\end{abstract}

\section{Introduction}

After first hints by the Frenchman Joseph Baptiste Fourier in 1824 that the atmosphere acts like a shield reducing the heat loss to space, the Irishman John Tyndall, working in Great Britain, formulated the first full definition of the greenhouse effect of the Earth's atmosphere in the Proceedings of the Royal Academy of Sciences in 1863:

The solar heat possesses the power of crossing an atmosphere, but, when the heat is absorbed by the planet, it is so changed in quality that the rays emanating from the planet cannot get with the same freedom back into space. Thus the atmosphere admits the entrance of the solar heat but checks its exit, and the result is the tendency to accumulate heat at the surface of the planet.

His formulation of the natural greenhouse effect is still a pertinent one. The first discussion on an anthropogenic contribution to the greenhouse effect by the Swedish scientist Arrhenius in 1896 gave already a first number of climate system sensitivity to a doubling of the carbon dioxide concentration in the atmosphere, which was only slightly above present-day estimates. It was only in 1938 that the British specialist on steam tables, Guy Callendar, gave a first full anthropogenic greenhouse effect assessment by relating the observed global mean warming in 
the first decades of the $20^{\text {th }}$ century to the still rather uncertain first observations of the carbon dioxide increase. The Second World War and a lack of evidence for a further near surface air temperature increase until the early 1970s have caused a nearly complete silence for the anthropogenic climate change debate.

Only via the outcome of international science conferences in the second half of the 1980s did the United Nations Environment Programme (UNEP) and the International Council of Scientific Unions (ICSU) stimulate the foundation of the now famous Intergovernmental Panel on Climate Change (IPCC) by UNEP and the World Meteorological Organization (WMO) in November 1988. Since then the first legal instruments of a global climate policy have evolved. It is fair to say that without the IPCC assessment reports we would not have a global climate policy concept and the - albeit - rather meagre implementation of so-called climate protection measures.

\section{The disturbed global carbon cycle}

In its fourth assessment report of 2007 the IPCC gave the schematic of Fig. 1 for the global carbon cycle reservoirs and annual fluxes between them, if of relevance for the timescale of the enhanced greenhouse effect of the atmosphere. It becomes clear from Fig. 1 that, firstly, fossil fuel burning accounts for about 80 percent of the anthropogenic carbon emissions into the atmosphere, secondly, the net uptake of anthropogenic emissions by vegetation surmounts the input into the atmosphere due to the destruction of vegetation and soil degradation, thirdly, the ocean takes up at present about a third of fossil fuel related carbon emissions, and fourthly, about 40 percent of all anthropogenic carbon emissions stay in the atmosphere. Carbon dioxide being an important greenhouse gas - second only to water vapour - such net emission raised the greenhouse effect of the atmosphere. This enhancement of the greenhouse effect must stimulate a mean global warming, if anthropogenic or natural cooling tendencies do not compensate.

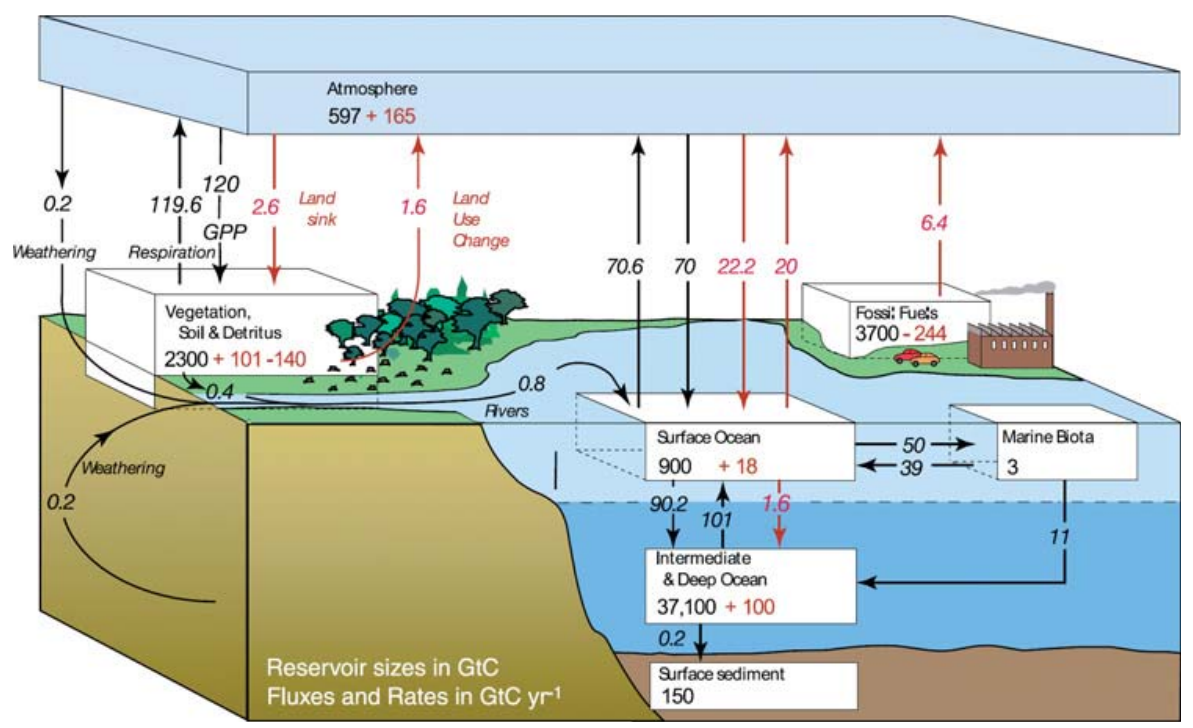

Fig. 1. The global carbon cycle for the 1990 s, showing the mean annual fluxes in Gt $\mathrm{C} \mathrm{yr}^{-1}$ : preindustrial natural fluxes in black and anthropogenic fluxes in red. The net terrestrial loss of $39 \mathrm{Gt} \mathrm{C}$ is inferred from cumulative fossil fuel emissions minus atmospheric increase minus ocean storage. The loss of $140 \mathrm{Gt} \mathrm{C}$ from the 'vegetation, soil, detritus' compartment represents the cumulative emissions from land use change and requires a terrestrial biosphere sink of $101 \mathrm{Gt}$ C. Gross fluxes generally have uncertainties of more than $\pm 20 \%$ (Source: IPCC 2007 [2]). 


\section{The disturbed radiation budget}

Carbon dioxide is not only the second most important greenhouse gas of the atmosphere but is also long-lived (1/e-times for different reservoirs above a few centuries). Therefore its concentration increase is changing the radiation budget of the Earth for a long time. The scientific community has listed in IPCC 2007 [2] the different anthropogenic warming and cooling influences by giving the so-called radiative forcing for each influencing factor. It is defined as the net radiation flux density change at the tropopause* and displayed in Fig. 2 together with the level of understanding. It is evident that methane $\left(\mathrm{CH}_{4}\right)$ and other long-lived greenhouse gases like nitrous oxide $\left(\mathrm{N}_{2} \mathrm{O}\right)$ as well as halocarbons add substantially with a share of about 40 percent to the accumulated radiative forcing of carbon dioxide since 1750. It becomes also clear that tropospheric ozone, as part of the photosmog nearly reaches the methane forcing and that two aerosol effects, both with on average negative radiative forcing, hence a stimulus for cooling, partly compensate the positive radiative forcing. Overall the net radiative forcing is - despite its large uncertainties for some components - positive.

In IPCC 2007 [2] this Fig. 2 was condensed into the following sentence:

The understanding of anthropogenic warming and cooling influences has improved since the third assessment report, leading to very high confidence that the global average net effect of human activities since 1750 has been one of warming, with a radiative forcing of $1.6 \mathrm{~W} / \mathrm{m}^{2}\left(0.6\right.$ to $\left.2.4 \mathrm{~W} / \mathrm{m}^{2}\right)$.

Radiative forcing by land-use change, black carbon on snow, and contrails are much smaller than from changed greenhouse gas concentrations and growing aerosol load. Also the Sun's contribution, a slight positive forcing, is secondary.

\section{Observed climate parameter changes}

If there is a net radiative forcing, the climate system has to react in order to reach in the long-term again zero net energy flux to space, when thermal radiation emitted to space equals solar input for the planet as a whole. Slowly reacting components will, however, delay the full response to the forcing, thus climate parameter observations will only describe a partial response to it. In other words: We are committed to more climate change, even if we could fully stop a further increase of the greenhouse gas concentrations. Up to now, i.e., at historical radiative forcing increase rates, the resulting mean global warming has reached $0.76 \pm 0.19^{\circ} \mathrm{C}$ until 2005 , the sea level rise rate has increased to about $3 \mathrm{~mm}$ per year in the period since 1992, from about $1.8 \mathrm{~mm}$ per year for the average of the $20^{\text {th }}$ century; furthermore the minimum Arctic sea ice extent in September shrank by about 11 percent per decade since 1978, when continuous observations with full coverage by satellite data started. Although the current sea level rise is mainly caused by thermal expansion of sea water, the contribution by melting mountain glaciers and smaller ice caps is not negligible (about $20 \mathrm{~mm}$ since 1960). Also the Greenland ice sheet $(0.21 \pm 0.07 \mathrm{~mm} / \mathrm{a})$ and the Antarctic ice sheet $(0.21 \pm 0.35 \mathrm{~mm} / \mathrm{a})$ have recently contributed, albeit fraught with large uncertainties.

In many regions the amount of rain per event has increased even when total precipitation did not change or has slightly decreased. Most subtropical areas saw a loss of precipitation in recent decades, higher northern latitudes and in parts the inner tropics an increase.

\section{Climate scenarios}

Anthropogenic climate change happens already now and the future climate largely depends on the way we humans use energy. We are clearly in a non-analogue climate state with further rapid changes in atmospheric composition, currently at 383 parts per million by volume (ppm) carbon dioxide concentration, which has never occurred over the recent millions of years when ice sheets existed at or close to both poles. In such a situation precise paleo-climate reconstructions are good test data for climate models but do not provide direct analogues for future climate.

Therefore, numerical models of the climate system based on first principles of physics have to project potential climate futures for given scenarios of human behaviour. IPCC 2000 [1] has 
A.

Radiative forcing of climate between 1750 and 2005

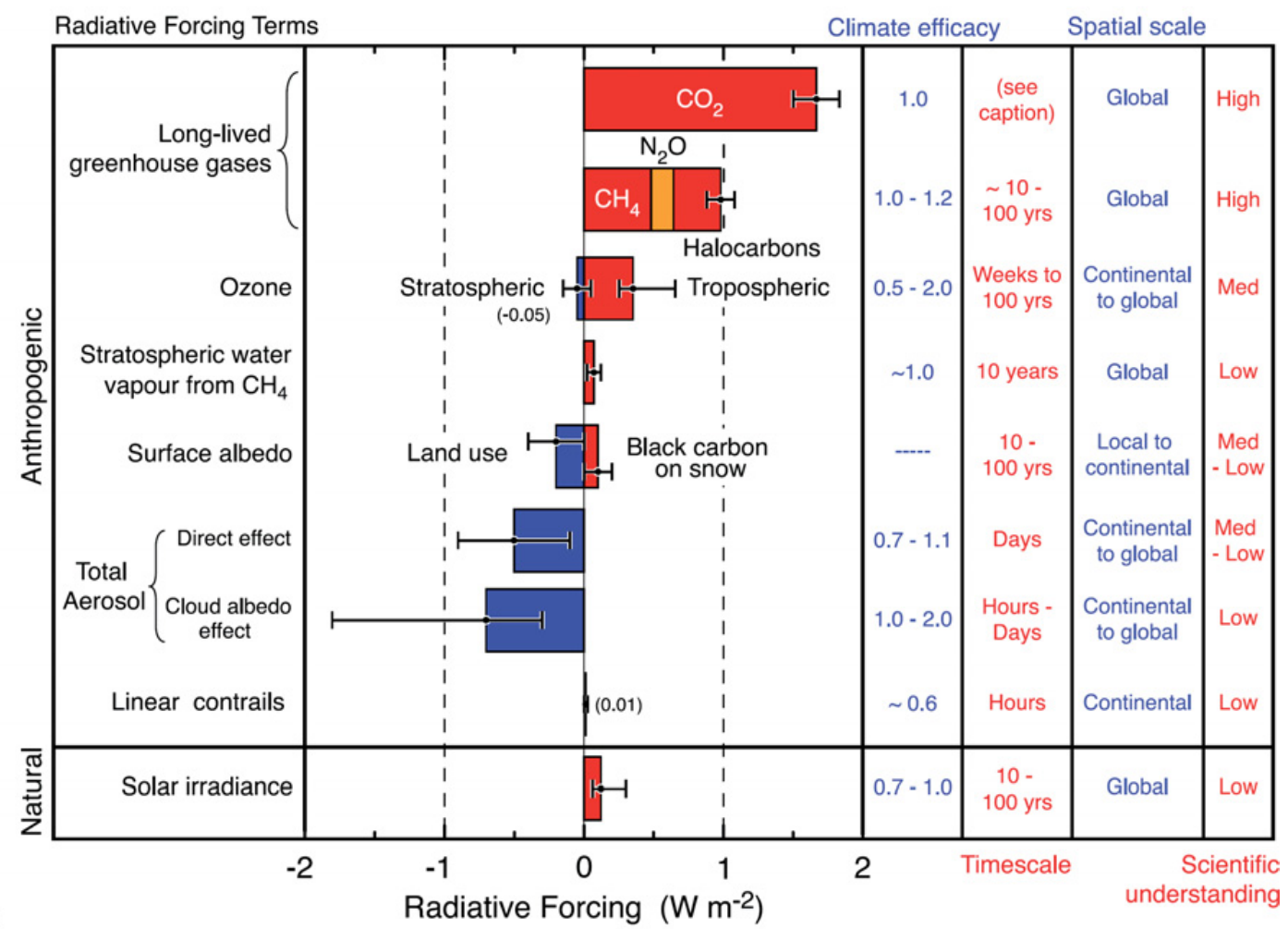

B.

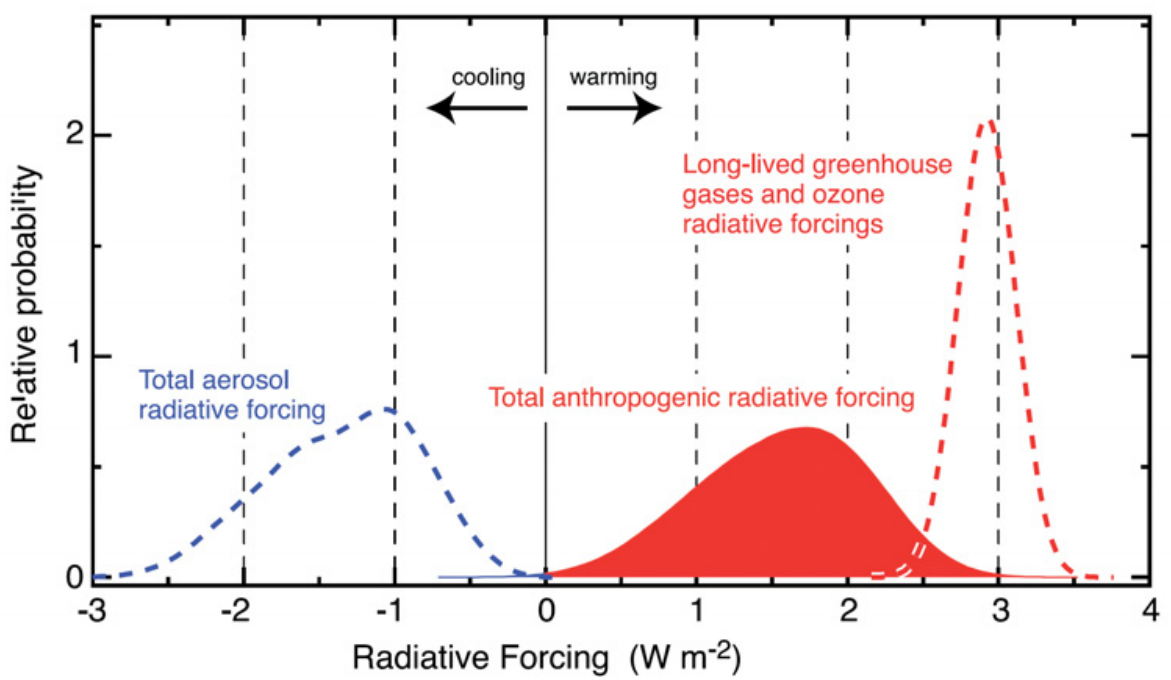

Fig. 2. Summary of the principal components of the radiative forcing of climate change for 2005 relative to the start of the industrial era (about 1750; upper graph). The only increase in natural forcing occurred in solar irradiance. Positive forcings lead to warming and negative ones to cooling. The thin black line attached to each bar represents the range of uncertainty. Probabilities of certain parts of the forcing (lower graph) (Source: IPCC 2007 [2]).

proposed such scenarios for greenhouse gas and tropospheric aerosol concentrations based on storylines for strongly differing global human development. For these scenarios without dedicated climate policies beyond the Kyoto Protocol the modeled mean global warming at the end of the $21^{\text {st }}$ century surmounts all rates of temperature change and absolute temperature 
values homo sapiens ever experienced. As Fig. 3 depicts, the modeled temperature changes for scenarios A2 and A1FI, within only a bit more than a century, are similar to the global mean temperature change during the 10,000 year transition from an intense glacial to an interglacial. The uncertainties in the results of at least 15 model groups participating (grey columns after the year 2000) are of similar magnitude as the differences in the emission scenarios. But Fig. 3 also shows the strong influence human behaviour could have. For the Gedankenexperiment 'stable greenhouse gas concentrations reached in 2000' (orange curve) global mean warming would continue over the entire $21^{\text {st }}$ century, demonstrating a delayed reaction, which is mainly caused by the slow mixing of the ocean.

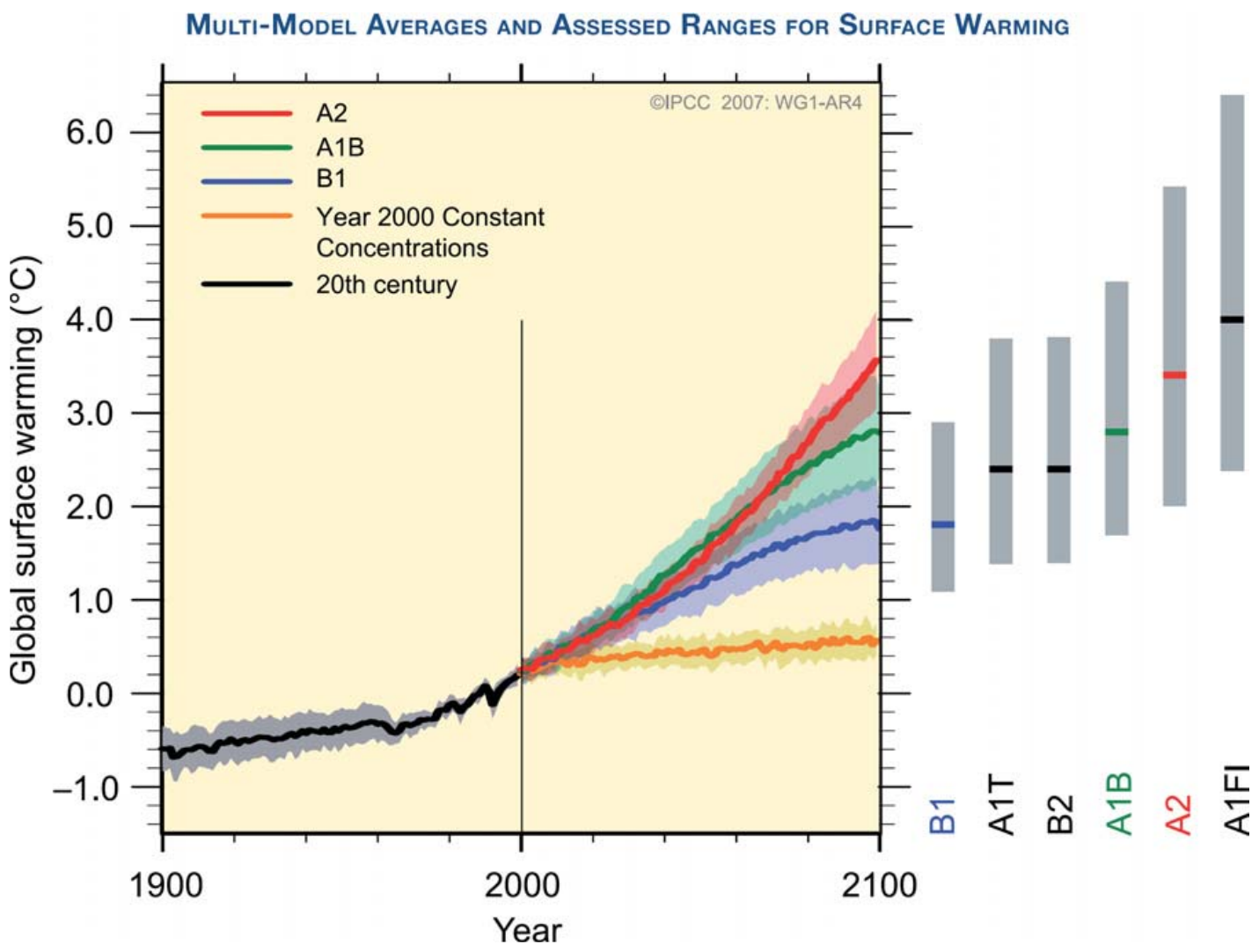

Fig. 3. Multi-model global averages (solid curves) of surface warming, relative to 1980-1999, for scenarios A2, A1B, B1, shown as continuations of simulations for the $20^{\text {th }}$ century. Shading denotes the \pm 1 standard deviation of individual model annual averages. The grey bars at right indicate the best estimate (solid lines) and the likely range for each scenario, with results from independent models and observational constraints being also included (Source: IPCC 2007 [2]).

Sea level rise (not shown) would continue over centuries, because large glaciers, small ice caps and ice sheets need a long time (up to millennia for large ice sheets) to adjust to ongoing warming. The rate of rise during the coming several centuries would largely depend on the reaction of the Greenland ice sheet as well as the Westantarctic ice shield. Both reactions are rather uncertain, but the potential sea level equivalent of about $6 \mathrm{~m}$ each clearly indicates the long-term threat for low-lying coastal areas and their megacities as well as island states.

However, the potentially largest threat in the $21^{\text {st }}$ century is the redistribution of precipitation on a global scale, as displayed in Fig. 4. I translate it into the following sentence: Regions with enough freshwater get more, areas with water shortage get less. In other words: Semi-arid tropical and subtropical areas become drier and parts of the inner tropics and especially high latitude regions become wetter (cf. article by J. Quade and W. S. Broecker, this volume). 


\section{Projected Patterns of Precipitation Changes}

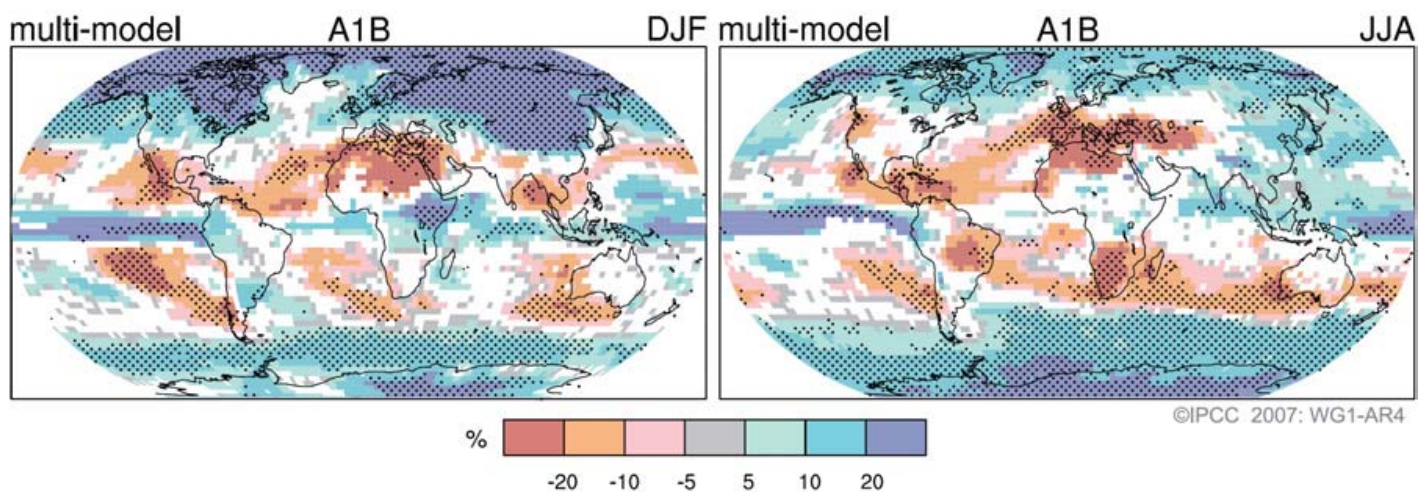

Fig. 4. Multi-model averages of precipitation changes in percent for the period 2090-2099, relative to 1980-1999 for scenario A1B, boreal summer (right) and winter (left). For the white areas less than two thirds of the models agree in the sign of the change and for stippled areas more than $90 \%$ of the models agree in the sign of the change (Source: IPCC 2007 [2]).

\section{Intermediate conclusions and decisions}

1) As the IPCC Working Group II on "Impacts, Vulnerability and Adaptation" stated: At a mean global warming above 1.5 to $2.5^{\circ} \mathrm{C}$ until the end of the $21^{\text {st }}$ century, 20 to 30 percent of all known species will be threatened by extinction (the two largest environmental problems are closely linked).

2) In view of the large amount of fossil fuels still available (especially coal) the reduction of fossil fuel use before the exhaustion of their deposits is a must, should a globally coordinated and effective climate policy become reality, as stipulated by the precautionary approach in the Rio Declaration and the United Nations Framework Convention on Climate Change (UNFCCC) and its Kyoto Protocol.

3) The complete overhaul of the global energy supply system that is necessary within the $21^{\text {st }}$ century meets many adversaries. Hence, before consensus is reached for a comparably stringent climate policy, innovative countries have to take the lead, as for example Germany did with its Feed-in Law in 1991 and its Renewable Energies Act since 2000 that have led to an increase of the share of renewable electric power from less than five percent (hydropower) to now about 15 percent.

4) The European Council has reacted to the IPCC findings by setting first binding European climate policy goals on 9 March 2007:

a) 20 percent reduction of $\mathrm{CO}_{2}$ emissions until the year 2020 with respect to emissions of 1990 (30 percent reduction promised if others, foremost USA and Japan, join)

b) 20 percent end-energy used in EU-27 must then be from renewable energy sources

c) An additional goal, which is not binding, and very hard to reach, is a 20 percent rise in energy efficiency until 2020 relative to that at the time of the decision.

5) Also the $13^{\text {th }}$ Conference of the Parties (COP13) to UNFCCC on Bali has set out goals to be fully negotiated until COP15 in Copenhagen in December 2009:

a) $\mathrm{CO}_{2}$ emission reduction between 25 and 40 percent to be achieved by the industrialized countries until 2020 in relation to the emissions of 1990

b) Integration of emerging countries like China, India, Brazil by first commitments, e.g., partial decoupling of yearly energy input growth rate from the economic growth rate

c) Partial financing of adaptation measures in developing countries using the revenues of the emissions trading schemes of the industrialized countries. 


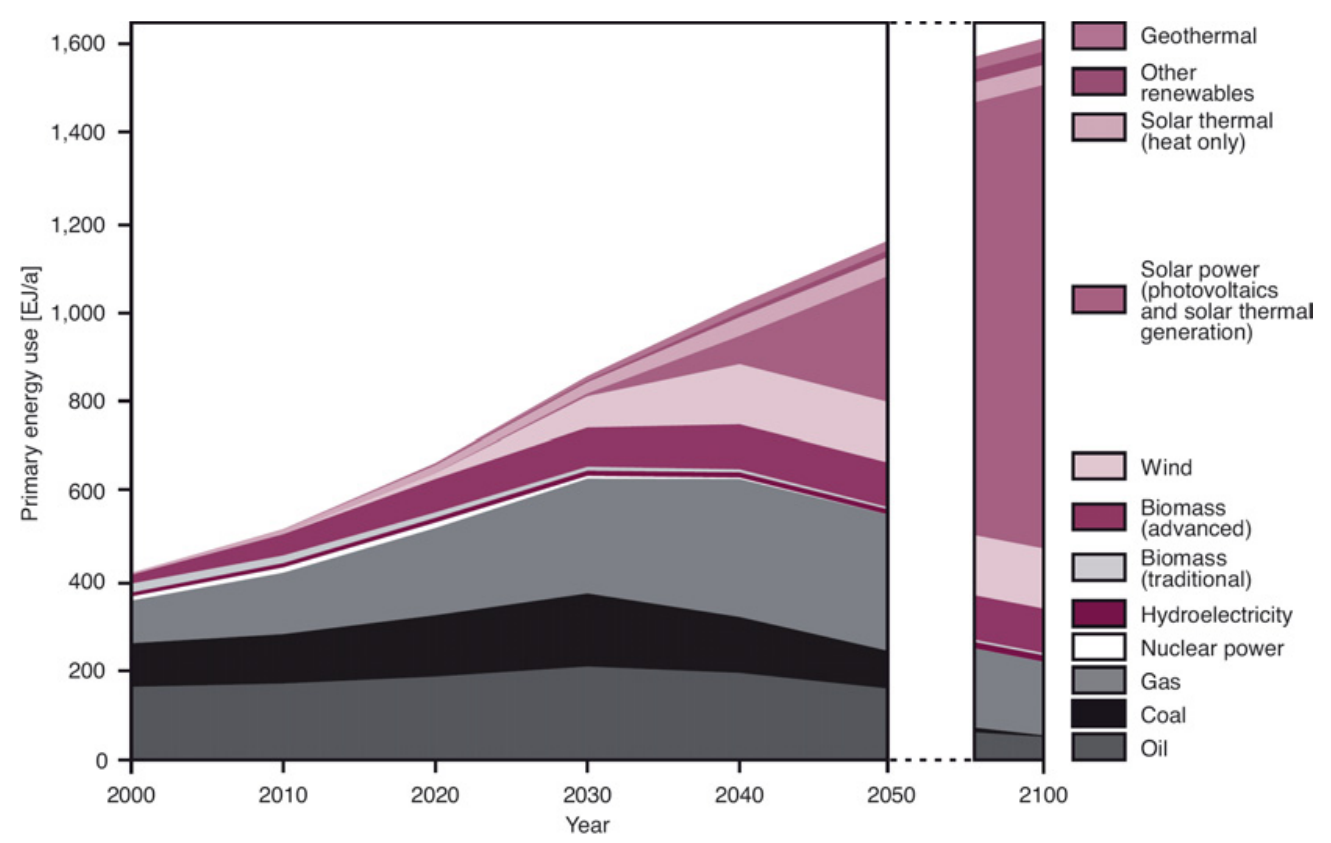

Fig. 5. Transforming the global energy mix: The exemplary path until 2050/2100 (Source: WBGU [5]).

\section{Is there a scenario keeping global mean warming until 2100 below $2{ }^{\circ} \mathrm{C} ?$}

The strong delay of visible consequences of climate policy measures (e.g., reduced sea level rise rate reaction being delayed by at least several decades) calls for a rapid reaction by the global community to be able to dampen the anthropogenic climate change rate at least for the next generation. To reach the $2{ }^{\circ} \mathrm{C}$ target, a required emission reduction by about 50 percent until 2050 has been claimed for years by scientists. That claim is however only valid, if climate system sensitivity is well below $3{ }^{\circ} \mathrm{C}$ for the full doubling of the carbon dioxide concentration from $280 \mathrm{ppm}$ (the pre-industrial value) to $560 \mathrm{ppm}$. Because IPCC 2007 [2] has announced that $3{ }^{\circ} \mathrm{C}$ is the most probable value, more stringent reduction goals are presumably necessary, also in view of the high probability for a massive Greenland ice sheet melting (irreversible for human time scales!) at global mean warming well below that for a doubling of the carbon dioxide concentration. In an attempt to supply such an energy scenario for entire mankind, the German Global Change Advisory Council of the Federal Government (Wissenschaftlicher Beirat Globale Umweltveränderungen der Bundesregierung = WBGU) embarked in 2001 for such a scenario development. In its report "A Sustainable Energy Path" of 2003 [5] it was shown that a global strong economic growth scenario with concomitant strong technology development, i.e. similar to the storyline of scenario A1T of the IPCC 2000 [1] scenarios, could well lead to a mean global warming of less than $2{ }^{\circ} \mathrm{C}$, if renewable energy research and implementation are strongly fostered globally (see Fig. 5 for the temporal evolution of this energy supply system for the $21^{\text {st }}$ century). Such an energy system overhaul would be much less costly than mere adaptation to climate change [6] as also the later more detailed study by Stern [4] underlined. The long-term guardrail for climate policy, namely equal emission rights for any person, mostly known as "contraction and convergence", would strongly ease climate policy implementation, as also proposed by WBGU for the above scenario.

\section{Outlook}

Anthropogenic climate change will hopefully stimulate societies to become solar energy societies again. All countries possess the "raw material": Solar energy and its derivatives, like wind and 
biomass. Hence the main future energy resource, direct solar radiation, is most plentiful for the nowadays poorest countries. A strong climate change policy can therefore lead to a peace dividend.

We have simply to learn until 2050 how to use one five thousandth of the Sun's offer of energy for then about 9 billion people, supplying $2 \mathrm{~kW}$ power per person on average.

\section{References}

1. IPCC, IPCC Special Report on Emission Scenarios, WMO, Geneva, Switzerland (2000)

2. IPCC, Climate Change 2007 - The Physical Science Basis, Contribution of Working Group I to the Fourth Assessment Report of the IPCC (Cambridge University Press), ISBN 978-0521-88009-1 (2007a)

3. IPCC, Climate Change 2007 - Impacts, Adaptation and Vulnerability, Contribution of Working Group II to the Fourth Assessment Report of the IPCC (Cambridge University Press), ISBN 978-0521-88010-7 (2007b)

4. Stern, Stern Review on the Economics of Climate Change (Cambrigde University Press), ISBN 0-521-70080-9 (2006)

5. WBGU, Towards Sustainable Energy systems (Earthscan, London), ISBN 1-85383-882-9 (2003a)

6. WBGU, Climate Protection Strategies for the $21^{\text {st }}$ Century (Kyoto and Beyond; WBGU, Berlin), ISBN 3-936191-04 (2003b) 